\title{
Optimasi Formula Gel Antioksidan Ekstrak Etanol Buah Bligo (Benincasa hispida) dengan Metode Simplex Lattice Design (SLD)
}

\author{
(Antioxidants Gel Formula Optimation of Bligo Fruit Ethanolic Extract (Benincasa \\ hispida) by Simplex Lattice Design (SLD) method)
}

\author{
Suryani*, Andi Nafisah, Syahrir Mana'an* \\ Jurusan Farmasi, Fakultas Farmasi, Universitas Halu Oleo, Kendari-Sulawesi Tenggara, Indonesia
}

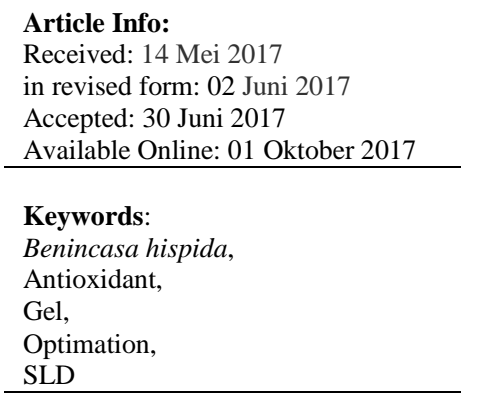

Corresponding Author:

Suryani

Jurusan Farmasi,

Fakultas Farmasi,

Universitas Halu Oleo,

Kendari-Sulawesi Tenggara,

Indonesia

Phone : +62 -85292216254

Email: soerysuer@yahoo.com

\begin{abstract}
Benincasa hispida has many benefits including as antioxidant. This study aims to evaluate the effect of Carbomer 940, HPMC and $\mathrm{NaOH}$ concentrations in antioxidant gel formula and to determine Carbomer 940, HPMC and $\mathrm{NaOH}$ concentrations that could produce the optimal antioxidant gel formula. Benincasa hispida was extracted by maceration method and antioxidant activity was tested by DPPH method. The antioxidant gels were formulated with variety combinations of Carbomer 940, HPMC and $\mathrm{NaOH}$. The optimal gel formula was obtained by Design Expert 7.1.5 with Simplex Lattice Design method. The physical characteristic of optimal gel formula was retested and compared with the results of Simplex Lattice Design.The results showed that antioxidant activity of Benincasa hispida ethanolic extract has potent activity with the $\mathrm{IC}_{50} 40,28 \mu \mathrm{g} / \mathrm{mL}$. The increasing concentration of Carbomer 940, HPMC and $\mathrm{NaOH}$ possessed the high coefficients viscosity (cPs) with the value of 4366, 4133 and 3750 respectively. The increasing concentration of $\mathrm{NaOH}$ possessed $\mathrm{pH}$ and dispersive power of the gel with coefficients of 11,0 and 5,21 respectively. The desirability values suggested by Simplex Lattice Design were 1,000 with component variation of the optimal formula were Carbomer 940 1,5\%, HPMC $0,5 \%$ and $\mathrm{NaOH} 0,4 \%$. The significance test of the optimal formula compared to the results of laboratory experiments showed the significance of viscosity of 0,130 , the dispersive power of 0,348 and $\mathrm{pH}$ of 0,184 that means there was no significant difference between the prediction values by using Simplex Lattice Design and results of laboratory experiments. It was indicated that significance values of each responses were over 0,05 ( $p>0.05)$.
\end{abstract}




\begin{abstract}
ABSTRAK
Buah Bligo diketahui memiliki banyak manfaat termasuk sebagai antioksidan. Penelitian ini bertujuan untuk mengetahui pengaruh konsentrasi Carbomer 940, HPMC dan $\mathrm{NaOH}$ terhadap formula gel antioksidan dan menentukan konsentrasi dari Carbomer 940, HPMC dan $\mathrm{NaOH}$ yang menghasilkan formula gel antioksidan yang optimum. Ekstrak etanol buah Bligo diperoleh dengan metode maserasi kemudian dilakukan uji aktivitas antioksidan ekstrak dengan metode DPPH. Formula gel antioksidan dibuat dengan variasi kombinasi Carbomer 940, HPMC dan $\mathrm{NaOH}$. Penentuan formula optimum gel dilakukan dengan menggunakan software Design Expert 7.1.5 metode Simplex Lattice Design. Formula optimum diuji kembali karakteristik fisiknya dan dibandingkan dengan hasil yang diperoleh menggunakan metode Simplex Lattice Design. Hasil penelitian menunjukan bahwa aktivitas antioksidan ekstrak etanol buah Bligo termasuk dalam kategori sangat kuat dengan nilai $\mathrm{IC}_{50}$ sebesar 40,28 $\mu \mathrm{g} / \mathrm{mL}$. Peningkatan konsentrasi Carbomer 940, HPMC dan $\mathrm{NaOH}$ meningkatkan viskositas dengan nilai koefisien masing-masing 4366, 4133 dan 3750. Peningkatan konsentrasi $\mathrm{NaOH}$ meningkatkan $\mathrm{pH}$ dan daya sebar gel dengan koefisien masing-masing 11.0 dan 5.21. Nilai desirability yang disarankan Simplex Lattice Design adalah 1,000 dengan variasi komponen dari formula optimum yaitu Carbomer 940 1.5\%, HPMC 0.5\% dan $\mathrm{NaOH} \mathrm{0.4 \% .} \mathrm{Pengujian} \mathrm{signifikansi} \mathrm{terhadap} \mathrm{prediksi}$ formula optimum dengan hasil percobaan laboratorium menunjukan signifikan dengan nilai viskositas sebesar 0.130 , daya sebar 0.348 dan $\mathrm{pH} 0.184$ yang berarti tidak ada perbedaan signifikan antara prediksi Simplex Lattice Design dengan hasil percobaan laboratorium yang ditunjukan dengan nilai signifikansi masing-masing respons lebih dari 0.05 .
\end{abstract}

Kata Kunci : Benincasa hispida, Antioksidan, Gel, Optimasi, SLD

\section{PENDAHULUAN}

Penuaan merupakan proses alamiah dalam kehidupan manusia. Penuaan dapat diartikan sebagai penurunan fungsi biologis dan kemampuan organisme untuk beradaptasi terhadap stres metabolik. Penuaan dapat mengakibatkan penurunan berbagai sistem dan fungsi tubuh sehingga menyebabkan munculnya berbagai penyakit. Menua erat kaitannya dengan berbagai proses degeneratif. Penyebab penuaan dikelompokkan menjadi faktor internal dan eksternal. Salah satu faktor internal penyebab penuaan adalah radikal bebas. Radikal bebas terjadi akibat proses oksidatif merupakan teori yang paling sering dianut. Produksi radikal bebas meningkat pada keadaan patologis akibat stres fisik maupun psikologis. Suatu kondisi dimana jumlah antioksidan lebih rendah dibandingkan radikal bebas disebut stres oksidatif. Banyak teori diajukan dan berbagai penelitian dilakukan untuk mencegah penuaan. Penggunaan antioksidan merupakan salah satu upaya yang sering dilakukan untuk mencegah penuaan atau setidaknya menua secara sehat. Antioksidan berperan sebagai penangkap efek buruk dari radikal bebas (Ardhie et al, 2011).

Antioksidan merupakan zat yang mampu melindungi sel melawan kerusakan yang ditimbulkan oleh radikal bebas (Reactive Oxygen Species), seperti singlet oksigen, superoksid, radikal peroksid dan radikal hidroksil. Penyinaran matahari yang berlebihan menyebabkan jaringan epidermis kulit tidak cukup mampu melawan efek negatif seperti kelainan kulit seperti dermatitis ringan sampai kanker kulit, sehingga diperlukan perlindungan baik secara fisik dengan menutupi tubuh misalnya menggunakan payung, topi atau jaket dan secara kimia misalnya dengan menggunakan kosmetik yang berfungsi sebagai antioksidan sehingga dapat melindungi kulit dari bahaya radiasi sinar matahari (Indika et al, 2012). Salah satu tanaman yang dapat menghasilkan antioksidan alami yaitu buah Bligo (Benincasa hispida) dengan kandungan Vitamin $\mathrm{C}$ yang dimilikinya (Garg et al, 2002). Vitamin ini dapat bekerja sebagai antioksidan dalam tubuh. Buah Bligo diketahui memiliki aktivitas antioksidan. Sifat antioksidan dari buah bligo berasal dari adanya senyawa polifenol seperti flavon (iso-vitexin) (Kumar et al, 2004). Optimasi dengan metode simplex lattice design bertujuan untuk menentukan konsentrasi bahan yang tepat sehingga akan diperoleh formula yang memiliki sifat fisik yang optimum dan respon yang diterima oleh konsumen. Metode Simplex Lattice Design (SLD) dapat digunakan untuk optimasi formula pada berbagai jumlah komposisi bahan yang berbeda sehingga menghasilkan formula 
optimum yang memiliki sifat-sifat fisik yang diharapkan. Metode ini cepat dan praktis karena dapat menghindarkan penentuan formula secara coba-coba (trial and error).

Berdasarkan uraian tersebut, peneliti tertarik untuk melakukan penelitian mengenai efektivitas formulasi sediaan gel antioksidan dari ekstrak buah Bligo. Penentuan formula optimum pada penelitian ini mengunakan metode Simplex Lattice Design (SLD) dengan tiga komponen bahan yang akan dioptimasi.

\section{METODE PENELITIAN}

Alat

Alat-alat yang digunakan pada penelitian ini meliputi spektrofotometer UV-Vis (Shimadzu V1800 ), rotary vaccum evaporator (Rotavapor ${ }^{\circledR} \mathrm{R}$ 300), tube, hot plate $\left(\right.$ Stuart $\left.^{\circledR}\right)$, stirrer (Model SS30), timbangan analitik (Precisa XB 220A ${ }^{\circledR}$ ) serta alat-alat gelas $\left(\right.$ Pyrex $\left.^{\circledR}\right)$.

\section{Bahan}

Bahan-bahan yang digunakan pada penelitian ini meliputi ekstrak buah Bligo (B. hispida), etanol $96 \%$, DPPH (2,2-diphenyl-1-picrylhydrazyl), akuades, $\mathrm{NaOH}$, Carbomer 940, HPMC, Metilparaben, Oleum rosae dan propilenglikol.

\section{Ekstraksi}

Ekstraksi dilakukan dengan metode maserasi selama $3 \times 24$ jam dengan penggantian pelarut setiap 1x24 jam. Ekstraksi dilakukan dengan menggunakan pelarut metanol $96 \%$ dalam wadah tertutup rapat dan tidak tembus cahaya.

\section{Uji aktivitas Antioksidan}

\section{Pembuatan Pereaksi DPPH 40 ppm}

Cara membuatnya adalah menimbang $2 \mathrm{mg}$ DPPH kemudian dilarutkan dalam etanol hingga semua larut, selanjutnya dimasukkan ke dalam labu takar $50 \mathrm{~mL}$ dan diencerkan hingga tanda tera. Kocok sampai homogen sehingga didapat larutan DPPH 40 $\mu \mathrm{g} / \mathrm{mL}$.

Pembuatan Larutan Blanko

Pembuatan larutan blanko dilakukan dengan cara memipet 1,0 mL larutan DPPH $40 \mathrm{ppm}$, dimasukkan ke dalam tabung reaksi dan ditambahkan 4,0 $\mathrm{mL}$ etanol, dikocok hingga homogen dan diinkubasi pada suhu $37^{\circ} \mathrm{C}$ selama 30 menit.
Pembuatan Larutan Stok 1000 ppm

Cara membuatnya adalah dengan menimbang 0,1 gram ekstrak etanol buah Bligo dan dilarutkan dalam etanol hingga larut, selanjutnya dimasukkan ke dalam labu takar $100 \mathrm{~mL}$ dan diencerkan hingga tanda tera.

Pembuatan Larutan Seri Bahan Uji

Dilakukan pengenceran pada larutan stok 1.000 ppm dengan cara memipet $0,5,1,2,4$, dan $8 \mathrm{~mL}$ larutan stok kemudian masing-masing dimasukan dalam labu ukur $10 \mathrm{~mL}$ untuk membuat konsentrasi 50, 100, 200, 400 dan 800 ppm. Setelah itu masingmasing konsentrasi diambil $1 \mathrm{~mL}$, dimasukan dalam tabung reaksi dan ditambahkan $1 \mathrm{~mL}$ DPPH kemudian ditambahkan lagi $3 \mathrm{~mL}$ etanol. Dikocok hingga homogen kemudian diinkubasi pada suhu $37^{\circ} \mathrm{C}$ selama 30 menit. Uji serapan dilakukan pada panjang gelombang $515,5 \mathrm{~nm}$.

Optimasi Formula

Penentuan formula optimum ditentukan oleh software Design Expert 7. 1. 5 dengan menggunakan metode Simplex Latice Design. Formula yang dihasilkan oleh Simplex Latice Design terdiri dari 7 formula dengan nomor urut (run) pembuatan. Tiga faktor komponen yang merupakan variabel bebas yakni Carbomer 940, HPMC dan $\mathrm{NaOH}$.

\section{HASIL DAN PEMBAHASAN}

Ekstraksi dilakukan dengan metode maserasi menggunakan pelarut etanol 96\%. Ekstrak kental yang diperoleh sebanya 56,4 gram kemudian dihitung persen rendemen ekstrak terhadapt berat sampel awal. Rendemen ketrak yang diperoleh sebesar 5,64 gram.

Uji aktivitas antioksidan ekstrak buah Bligo dilakukan secara kuantitatif dengan menggunakan Spektrofotometer UV-Vis. Pengujian secara kuantitatif ini dilakukan untuk mengetahui serapan DPPH yang tersisa setelah ditambahkan ekstrak buah Bligo. Jika suatu sampel diketahui memiliki aktivitas antioksidan, maka akan terjadi penurunan nilai serapan DPPH pada rentang panjang gelombang $515,5 \mathrm{~nm}$. Hasil uji aktivitas antioksidan secara kuantitatif menunjukkan bahwa ekstrak etanol buah Bligo memiliki aktivitas antioksidan dengat kategori kuat dengan nilai $\mathrm{IC}_{50} 40,28 \mathrm{ppm}$. Adanya aktivitas antioksidan buah Bligo menurut penelitian Kumar dan Ramu (2004) disebabkan buah bligo mengandung senyawa polifenol seperti flavon (iso- 
vitexin) yang berkhasiat sebagai antioksidan.

Penentuan formula optimum ditentukan oleh software Design Expert 7. 1. 5 dengan menggunakan metode Simplex Latice Design. Formula yang dihasilkan oleh Simplex Latice Design terdiri dari 7 formula dengan nomor urut (run) pembuatan. Tiga faktor komponen yang merupakan variabel bebas yakni Carbomer 940, HPMC dan $\mathrm{NaOH}$. Nilai variabel terikat dan variabel bebas pada Simplex Latice Design berguna dalam menentukan formula optimum dapat dilihat pada Tabel 1.

Tabel 1. Variabel Bebas dan Variabel Terikat pada SLD untuk Menentukan Formula Optimum

\begin{tabular}{cccc}
\hline Variabel Percobaan & \multicolumn{3}{c}{ Batasan } \\
\hline Variabel bebas & $\begin{array}{c}\text { Komposisi } \\
\text { Rendah }\end{array}$ & Komposisi Tinggi & Target \\
\hline Carbopol 940 & $1 \%$ & $1.5 \%$ & In range \\
HPMC & $0.5 \%$ & $1 \%$ & In range \\
NaOH & $0.4 \%$ & $0.9 \%$ & In range \\
\hline Variabel Terikat & Batas Bawah & Batas Atas & Target \\
\hline Daya sebar & $5.8 \mathrm{~cm}$ & $7.0 \mathrm{~cm}$ & In range \\
pH & 4 & 6.8 & In range \\
Viskositas & 2000 & $6000.0 \mathrm{dPa} . \mathrm{s}$ & In range \\
& $\mathrm{cPa} . \mathrm{s}$ & & \\
\hline
\end{tabular}

Diantara ketiga komponen variabel terikat pada Tabel 1 harus menunjukan persyaratan yang memenuhi sebagian sediaan gel antioksidan. Daya sebar merupakan kemampuan gel untuk disebarkan di permukaan kulit. Gel yang baik memiliki daya sebar yang luas dalam rentang waku yang sempit selama proses penyebaran gel pada permukaan kulit. Nilai daya sebar gel yang baik berkisar antara 4-5 $\mathrm{cm}$. Daya sebar gel berbanding terbalik dengan viskositas. Semakin besar daya sebar gel, viskositas sediaan semakin kecil (Indika et al, 2012). Nilai pH untuk sediaan topikal harus berada dalam kisaran $\mathrm{pH}$ balance yang sesuai dengan $\mathrm{pH}$ kulit yaitu 4,5-6,5. Nilai $\mathrm{pH}$ tidak boleh terlalu asam karena dapat menimbulkan iritasi

pada kulit dan sebaliknya tidak boleh terlalu basah karena dapat menyebabkan kulit bersisik (Ainaro et al, 2015).

Nilai karakteristik fisik (variabel terikat) sediaan yang digunakan dalam metode Simplex Lattice Design untuk memperoleh formula optimum dapat dilihat pada Tabel 2.

Tabel 2. Nilai tiap-tiap karakteristik fisik sediaan gel antioksidan

\begin{tabular}{ccccc}
\hline Formula & Run & Viskositas (dPa.s) & Daya sebar $(\mathbf{c m})$ & pH \\
\hline 1 & 1 & $4366 \pm 115.4$ & $4.14 \pm 0.09$ & $5.86 \pm 0.28$ \\
2 & 3 & $4200 \pm 100$ & $4.59 \pm 0.10$ & $6.24 \pm 0.17$ \\
3 & 5 & $4750 \pm 50$ & $4.3 \pm 0.17$ & $7.45 \pm 0.12$ \\
4 & 6 & $4133 \pm 152$ & $4.83 \pm 0.15$ & $7.0 \pm 0.2$ \\
5 & 2 & $3566 \pm 208$ & $5.49 \pm 0.07$ & $10.5 \pm 0.05$ \\
6 & 7 & $4466 \pm 152$ & $4.49 \pm 0.13$ & $7.27 \pm 0.14$ \\
7 & 4 & $243.3 \pm 5.8$ & $5.21 \pm 0.11$ & $11.6 \pm 0.26$ \\
\hline
\end{tabular}

\subsection{Formula Optimum}

Prediksi formula optimum dari gel antioksidan ekstrak etanol buah Bligo dilakukan dengan menggunakan software Design Expert 7.1.5 yaitu pada Simplex Latice Design. Berdasarkan analisis software tersebut diperoleh nilai desirability dari formula optimum yang dapat dilihat pada Gambar 1. 


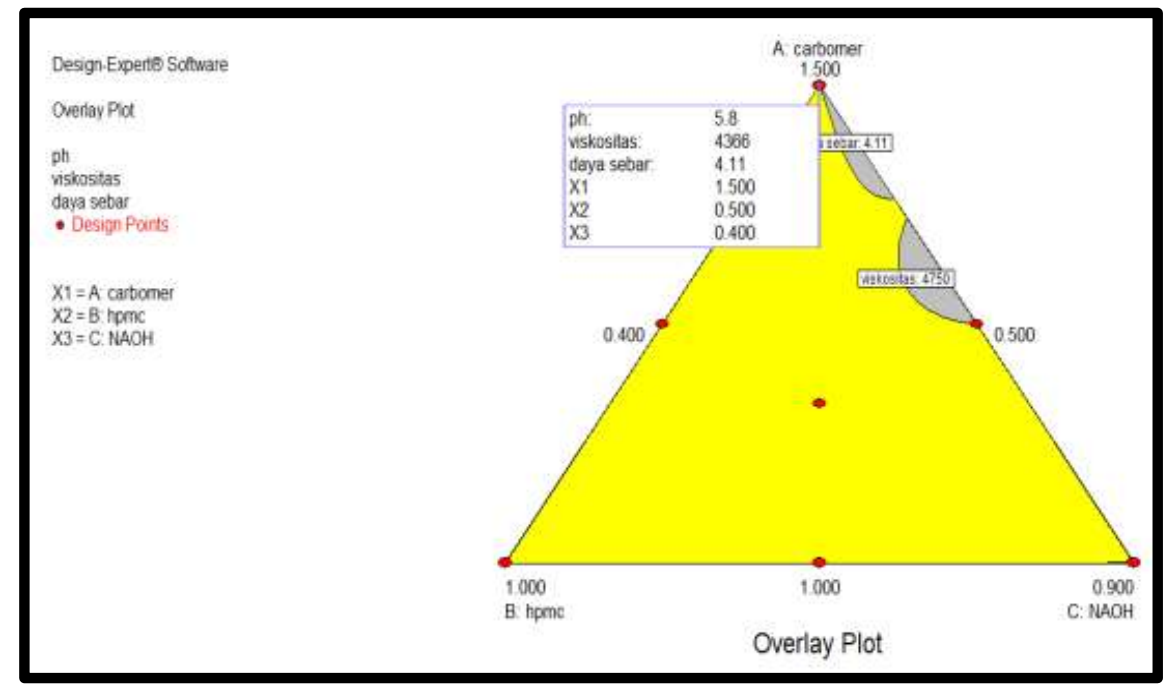

Gambar 1. Contour Plot Desirability Formula Optimum

Nilai desirability yang paling tinggi yaitu satu (Gambar 1). Nilai dari desirability maksimal adalah satu. Semakin mendekati satu, nilai desirability tersebut semakin baik. Hasil contour plot formula optimum pada Gambar 12 diperoleh daerah optimum (daerah berwarna merah) berdasarkan karakteristik fisik gel antioksidan yang memenuhi persyaratan yang telah ditetapkan. Luasnya daerah optimum (daerah berwarna merah) mengindikasikan bahwa cukup banyak kemungkinan formula optimum yang dapat diperoleh dan memenuhi persyaratan yang telah ditetapkan. Berdasarkan titik daerah optimum tersebut maka diperoleh komposisi optimum gel antioksidan yang dapat dilihat pada Gambar 2.

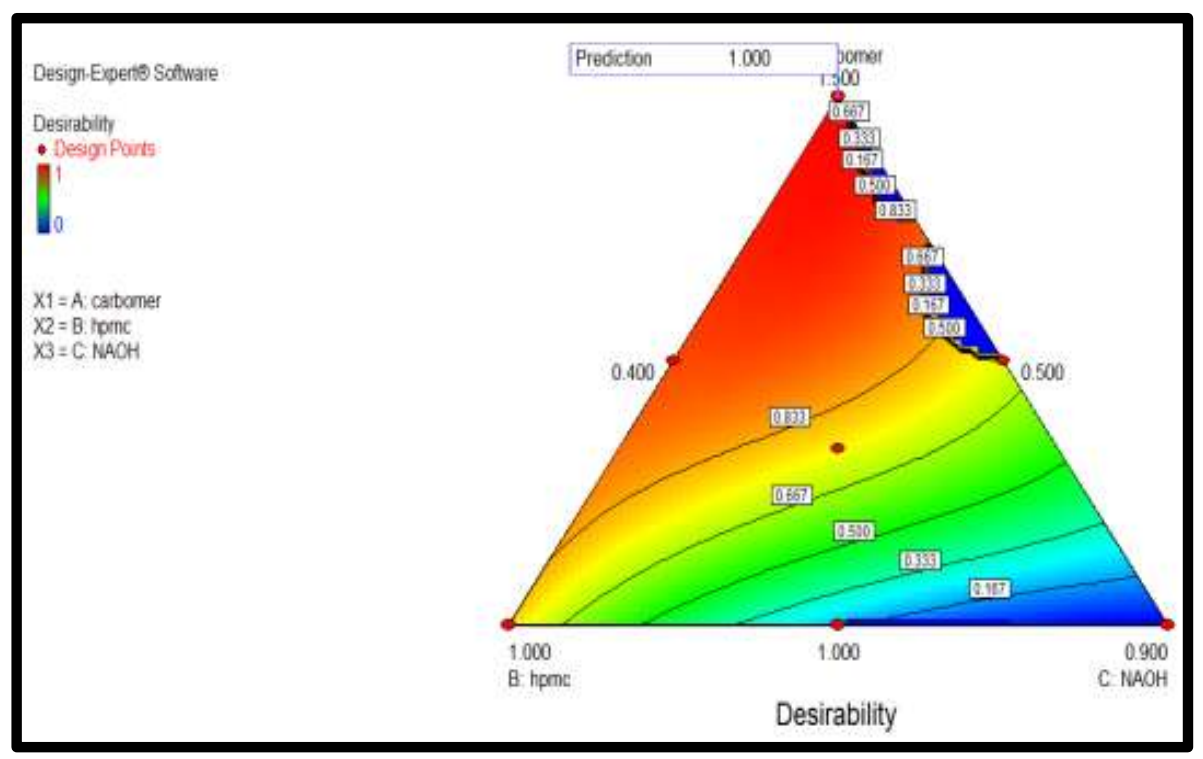

Gambar 2. Superimposed dari Contour plot Respon Viskositas, Daya Sebar dan $\mathrm{pH}$ 
Superimposed dari contour plot semua respon yaitu, viskositas, daya sebar dan $\mathrm{pH}$ sediaan gel antioksidan buah Bligo, sebagaimana yang terlihat pada Gambar 2. Superimposed merupakan penjabaran nilai desirability.Superimposed menampilkan nilai masing-masing variabel terikat dan bebas dari nilai desirability. Komposisi formula optimum dari superimposed untuk nilai desirability 1 sebagai berikut.

Tabel 3. Komposisi formula optimum dari superimposed

\begin{tabular}{cc}
\hline Bahan & Konsentrasi \\
\hline Ekstrak etanol Buah Bligo & $0.004 \%$ \\
Carbomer 940 & $1.5 \%$ \\
HPMC & $0.5 \%$ \\
NaOH & $0.4 \%$ \\
Propilenglikol & $10 \%$ \\
Metilparaben & 0.09 gram \\
Minyak melati & q.s \\
Aquadest & Ad 100 gram \\
\hline
\end{tabular}

Superimposed merupakan penjabaran dari nilai desirability. Superimposed menampilkan nilai masing-masing variabel terikat dan variabel bebas dari nilai desirability. Berdasarkan formula optimum, prediksi respon dari komposisi formula tersebut adalah viskositas sebesar 4366 c.Ps, daya sebar sebesar 4,11 cm dan $\mathrm{pH} 5,8$.
Verifikasi Formula Optimum Menggunakan Statistik

Prediksi respon yang dihasilkan dari Simplex Latice Design kemudian dibandingkan dengan respon hasil percobaan. Analisis statistik yang digunakan adalah uji-t one sample. Uji-t one sample digunakan untuk menguji signifikansi beda rata-rata antara tiap nilai hasil percobaan yang telah dilakukan dengan nilai teoritis hasil prediksi dari Simplex Latice Design.

Tabel 4. Verifikasi Hasil Optimasi Menggunakan Uji-t One Sample

\begin{tabular}{ccccc}
\hline Respon & Prediksi & Percobaan & Signifikansi & Kesimpulan \\
\hline Viskositas (dPa.s) & 4366 & $4273 \pm 64.29$ & 0.130 & Tidak signifikan \\
Daya sebar (cm) & 4.11 & $4.38 \pm 0.39$ & 0.348 & Tidak signifikan \\
pH & 5.8 & $5.84 \pm 0.04$ & 0.184 & Tidak signifikan \\
\hline
\end{tabular}

Tabel 4 menunjukkan bahwa respon daya sebar, viskositas dan $\mathrm{pH}$ menunjukkan hasil yang tidak berbeda signifikan antara prediksi dengan metode Simplex Lattice Design dengan hasil percobaan. Hal tersebut terlihat dari nilai signifikansi masing-masing respon yang lebih dari 0,05 . Tidak adanya perbedaan signifikan antara prediksi Simplex Lattice Design dengan hasil percobaan dapat disimpulkan bahwa software tersebut valid digunakan untuk mengoptimasi sediaan gel antioksidan ekstrak etanol buah Bligo.

\section{KESIMPULAN}

A. Konsentrasi Carbomer 940, HPMC dan $\mathrm{NaOH}$ memberikan pengaruh terhadap karakteristik fisik sediaan gel antioksidan yang meliputi viskositas, daya sebar dan $\mathrm{pH}$ masing-masing sebagai berikut:

1) Carbomer 940, HPMC dan $\mathrm{NaOH}$ berpengaruh terhadap peningkatan viskositas dengan nilai koefisien masingmasing 4366, 4133 dan 3750. Interaksi Carbomer 940-HPMC dan HPMC-NaOH menurunkan viskositas dengan koefisien 198,00 dan -1502,00. Interaksi Carbomer 940-NaOH dan Carbomer 940-HPMC$\mathrm{NaOH}$ meningkatkan viskositas dengan koefisien 2768,00 dan 7137,00.

2) Carbomer 940, HPMC dan $\mathrm{NaOH}$ mempengaruhi peningkatan daya sebar dengan koefisien masing-masing 4,11, 4,83 
dan 5,21. Interaksi Carbomer 940-HPMC dan HPMC-NaOH meningkatkan daya sebar dengan koefisien 0,36 dan 1,80 sedangkan interaksi Carbomer 940-NaOH dan Carbomer 940-HPMC-NaOH menurunkan daya sebar dengan koefisien 1,44 dan $-8,28$.

3) Ketiga bahan juga meningkatkan $\mathrm{pH}$ dengan koefisien 5,80, 7,00 dan 11,60. Interaksi HPMC-NaOH meningkatkan $\mathrm{pH}$ dengan koefisien 4,80. Interaksi Carbomer 940-HPMC, Carbomer 940-NaOH dan Carbomer 940-HPMC-NaOH menurunkan pH masing-masing 0,80, 5,20 dan 21,60

B. Kosentrasi ketiga bahan yang menghasilkan formula optimum masing-masing 1,5\%, $0,5 \%$ dan $0,4 \%$.

\section{DAFTAR PUSTAKA}

Ainaro, E.P., Gadri, A., Priani, S.E. (2015). Formulasi Sediaan Masker Gel Peel-Off Mengandung Lendir Bekicot (Achatina Fulica
Bowdich) sebagai Pelembab Kulit, Pros. Penelit. Spes. Unisba.

Anjarsari, E.Y., Yonika A.L., Fikri, A. (2012). Masker Antioksidan dan Anti Aging Berbasis Modernisasi Bahan Alam Indonesia, Bimfi, 1(1).

Ardhie, Ari, Muhandari. (2011). Radikal Bebas dan Peran Antioksidan dalam Mencegah Penuaan. Medicinus. 24 (1).

Garg, A., D. Aggarwal., S. Garg., Sigla A.K. (2002). Spreading of Semisolid Formulation,USA: Pharmaceutical Technology. Pp. 84-104.

Indika, O.M., dan Arif F.M. (2012). Pengaruh Suplementasi Vitamin C Terhadap Kapasitas Vital Paru Pada Perokok, Scientia, 2(1).

Kumar, A., dan P. Ramu. (2004). Anti-convulsant activity of Benincasa hispida fruit methanol extract, Journal of Natural Remedies, 4(2). 